\title{
Skeletal muscle index and its association with mobility among community-dwelling older women
}

\author{
Zbigniew M. Ossowski \\ Gdansk University of Physical Education and Sport, Gdansk, Poland
}

\section{abstract}

Background: The loss of muscle function and reduced mobility levels are the main reasons for the limitations of independence and disability in older people. The main aim of this study was to determine the relationship between the skeletal muscle index and mobility in older women.

Material and methods:

The study involved 166 older women. Skeletal muscle mass and other body components were determined by bioimpedance using an InBody 720 device. Functional mobility was evaluated with the timed up-and-go test. 30-second chair stand was also used to measure the level of functional strength in lower extremities.

Results: The skeletal muscle index was positively correlated with functional mobility $(r=-0.22 ; p=0.00)$ and 30 -second chair stand $(r=-0.47 ; p=0.00)$. However, the strength of lower extremities was a significantly better parameter in predicting mobility in older women than the skeletal muscle index and skeletal muscle mass.

Conclusions: The functional strength of lower extremity muscles and the skeletal muscle index can have a positive effect on functional mobility in older people. The results may be helpful in clinical practice when diagnosing mobility limitations and in the process of programming physical activity of older women aimed at the prevention of sarcopenia.

Key words: muscle mass, strength, gait, falls, sarcopenia, elderly.

\section{article details}

Article statistics: Word count: 2,355; Tables: 2; Figures: 1; References: 40

Received: December 2020; Accepted: February 2021; Published: March 2021

Full-text PDF: http://www.balticsportscience.com

Copyright @ Gdansk University of Physical Education and Sport, Poland

Indexation: Celdes, Clarivate Analytics Emerging Sources Citation Index (ESCI), CNKI Scholar (China National Knowledge Infrastructure), CNPIEC, DOAJ, EBSCO - Central \& Eastern European Academic Source, EBSCO - SPORTDiscus, EBSCO Discovery Service, Google Scholar, Index Copernicus, J-Gate, Naviga (Softweco, Primo Central (ExLibris), ProQuest - Family Health, ProQuest - Health \& Medical Complete, ProQuest - Illustrata: Health Sciences, ProQuest Nursing \& Allied Health Source, Summon (Serials Solutions/ProQuest, TDOne (TDNet), Ulrich's Periodicals Directory/ ulrichsweb, WorldCat (OCLC)

Funding: This research was funded by Gdansk University of Physical Education and Sport within the framework of the EU project entitled "Active lifestyles and predictors of risk for incapacity on senior population - RISINC2013".

Conflict of interests: Author has declared that no competing interest exists.

Zbigniew Ossowski, Faculty of Physical Culture, Gdansk University of Physical Education and Sport, Poland; Kazimierza Górskiego 1, 80-336 Gdańsk, Poland; tel. (+48) 505113037; e-mail: zbigniew.ossowski@awf.gda.pl

Open Access License: This is an open access article distributed under the terms of the Creative Commons Attribution-Non-Commercial-NoDerivatives 4.0 International (https://creativecommons.org/licenses/by-nc-nd/4.0/), which permits use, distribution and reproduction in any medium, provided the original work is properly cited, the use is non-commercial and is otherwise in compliance with the license. 


\section{INTRODUCTION}

Symptoms accompanying aging include loss of skeletal muscle mass (SM), strength and muscle function, known as sarcopenia [1,2]. The actual decrease in SM is observed after the fifth decade of life. Jansen et al. report that it is $1.9 \mathrm{~kg} /$ decade in men and $1.1 \mathrm{~kg} /$ decade in women [3]. According to other reports, in the age group of 20-80 years, there is a $30 \%$ to $50 \%$ decrease in $\mathrm{SM}$, and about $20 \%$ decrease in the striated muscle crosssection $[4,5]$.

Age-related deterioration of the muscle function is associated with functional impairment of the elderly, understood as the inability to perform basic activities of daily living. Mobility seems to play a major role among these abilities [6].

It has been demonstrated that reduced SM and muscle strength, among others, cause mobility limitations [7], increase the risk of falls [8, 9, 10] and are associated with high morbidity and mortality [11]. Other studies indicate that sarcopenia is associated with locomotive syndrome development $[12,13]$. The incidence of locomotive syndrome in patients with sarcopenia is 4-6 times higher than in those without sarcopenia [14]. It is worth emphasizing that women are more susceptible to the aforementioned consequences of sarcopenia, including mobility limitations, due to their reduced muscle reserve resulting from differences in anabolic hormone production [15].

The diagnostics of sarcopenia is based on quantitative determination of muscle mass, based on the skeletal muscle index (SMI), and assessment of strength and physical fitness [16]. Studies suggest that SMI (based on the quotient of SM and body height) is a better parameter to predict sarcopenia than SM [1]. Assuming that people with sarcopenia are much more likely to experience mobility limitations, the question arises whether SMI can be a sufficient parameter to predict the level of functional mobility in older women. There are no studies on this subject in the literature.

Moreover, the analysis of the literature on the subject shows areas of knowledge not yet fully explained. There is a lack of consistency in the results concerning the relationship between the mobility measured by the timed up-and-go test (TUG) and the level of lower extremity strength. Some researchers demonstrated a significant correlation between TUG results and knee extension force [17], while others did not observe such a correlation [18].

Establishing the relationship between SM, SMI and strength with mobility levels can be crucial in diagnosing mobility constraints, which is of great clinical importance. The obtained results can also be helpful in the work of trainers and therapists when programming exercise loads aimed at prevention of mobility limitations and sarcopenia in elderly women.

The main aim of the study was to determine the relationship between SMI and mobility levels in elderly women. The additional objective was to investigate the relationship between the results of TUG and the functional strength of the lower extremities in the subjects.

\section{MATERIAL AND METHODS}

\section{ETHIC STATEMENT}

The study protocol was approved by the Institutional Review Board at the Regional Medical Chamber in Gdansk (decision no. KB-29/14). 


\section{PARTICIPANTS}

The study involved 166 postmenopausal women $(\mathrm{M}=67.54$ years, $\mathrm{SD}=5.3)$. Participant recruitment was conducted at the Universities of the Third Age (UTA) in Gdańsk and Sopot and by means of advertisements placed in medical clinics and notice boards in housing estates. The criterion for inclusion in the study was postmenopausal age (women who did not have menstruation for at least 12 months). Moreover, women who did not receive a doctor's consent to participate in the study project were excluded from the study.

The characteristics of women, including selected morphological components and physical fitness, are presented in the table below (Table 1).

Table 1 Characteristics of morphological components and physical fitness of the studied women

\begin{tabular}{lccc}
\multicolumn{1}{c}{ Variables } & M & Me & SD \\
\hline Age $[$ years] & 67.54 & 66 & 5.3 \\
BM $[\mathrm{kg}]$ & 68.9 & 67.7 & 11.5 \\
Height $[\mathrm{cm}]$ & 159.65 & 160 & 6 \\
BMI $\left[\mathrm{kg} / \mathrm{m}^{2}\right]$ & 27.02 & 26.8 & 4.25 \\
SM $[\mathrm{kg}]$ & 23.28 & 23.4 & 2.68 \\
SMI $\left[\mathrm{kg} / \mathrm{m}^{2}\right]$ & 7.29 & 7.27 & 0.69 \\
PK HS $[\mathrm{kg}]$ & 23.11 & 22.91 & 3.3 \\
PK HS/BM $[\mathrm{kg}]$ & 0.34 & 0.34 & 0.07 \\
GS $[\mathrm{m} / \mathrm{s}]$ & 1.7 & 1.65 & 0.25 \\
TUG $[\mathrm{s}]$ & 5.77 & 5.66 & 0.84 \\
CST $[\mathrm{rep} / \mathrm{s}]$ & 17.53 & 17 & 3.74 \\
\hline
\end{tabular}

Abbreviations: BM - body mass; BMI - body mass index; SM - skeletal muscle mass; SMI - skeletal muscle mass index; PK - maximum peak; HS - handgrip strength; GS - gait speed, TUG - timed-up-and-go; CST - 30-second chair stand; M - mean; Me - median; SD - standard deviation.

The analysis showed that the average results of SMI demonstrated absence of sarcopenia in the subjects. The average SMI values were slightly higher than the threshold values adopted as diagnostic criteria for sarcopenia in Poland, i.e. $7.12 \mathrm{~kg} / \mathrm{m} 2$ [19]. The cut-off thresholds for the maximum force measured in the handgrip strength (HS) test and the gait speed (GS) determined in the GS test also confirmed absence of sarcopenia in women [20]. The mobility rate (PK HS/BM) provided information that the examined persons were not directly at risk of mobility limitations (the cut-off threshold is $0.281 \mathrm{~kg}$ ) [21]. The average measurement result for functional strength of the lower extremities was 17.53 repetitions and the mobility level measured in the TUG test was $5.77 \mathrm{~s}$. BMI values also showed that women were overweight.

\section{MeAsurements}

Body mass (BM) and skeletal muscle mass (SM) were analyzed using InBody 720 body composition analyzer (Biospace, Seoul, Korea). The SMI recommended by the European Working Group on Sarcopenia in Older People (EWGSOP) was used based on the equation: muscle mass/height2 $(\mathrm{kg} / \mathrm{m} 2)$ [16]. Body height $(\mathrm{cm})$ was measured in an anthropometric position without shoes, with an accuracy of $1 \mathrm{~mm}$. The body mass index (BMI) was defined with the equation: body weight/height2 $(\mathrm{kg} / \mathrm{m} 2)$.

Functional mobility was determined using the timed-up-and-go test (TUG). The participants were instructed to get up from the chair, walk around a cone placed $3 \mathrm{~m}$ in front of the chair, moving as fast as possible, while taking care not to run, and return to the starting position (sitting on the chair) [22]. The time (s) needed to complete the task was recorded. The participants made three attempts, and the fastest attempt was used for analysis. The TUG test is one of the determinants of sarcopenia in hospitalized patients at the age of 70 [23]. 
The 30-second chair stand (CST) from the Senior Fitness Test battery, determining the level of lower extremity functional strength was also used in the study [24]. CST measured the number (repetitions) of full stands that were completed in 30 seconds with the arms folded across the chest.

In order to characterize women in detail, the study was extended to include a muscle strength test - handgrip strength (HS) and gait speed (GS). Using these tests is recommended by the EWGSOP to diagnose sarcopenia.

The HS was performed with a digital hand dynamometer (SAEHAN, Changwon, Korea). During the test, the participants squeezed the dynamometer in their right hand in a standing position. The best result from 3 test runs was taken into account in the characteristics of the subjects, determining the peak value (max. peak (PK)) recorded in kilograms $(\mathrm{kg})$. Moreover, the HS/BM muscle strength index $(\mathrm{kg})$ was calculated, in case of which the relation to mobility limitations in older women was confirmed by Chinese researchers [21]. The strength of upper extremities measured by the HS test and the strength of knee joint extensors are important indicators of functional efficiency in older people [25].

The GS test determines the best time needed to cover a distance of 6 meters (m/s). GS is considered to be an indicator of mobility reduction and mortality in the elderly population [26].

\section{STATISTICAL ANALYSIS}

The normal distribution of features was verified using the Shapiro-Wilk test. The test of the relationship between the selected variables was carried out using correlation analysis in which, according to the literature, the correlation coefficient is indicated by the letter " $r$ " and the test probability by " $p$ ". The significance of the differences between the correlation strength ( $r$ ) was determined using differential tests for the dependent correlation coefficients b ased o $\mathrm{n} F$ isher's t ransformation. S tatistical a nalyses w ere performed using StatSoft, Inc. STATISTICA software, version 13.1.

\section{RESULTS}

The results of the correlation between TUG, muscle mass and strength are presented in Table 2 and Figure 1.

Table 2. Correlation results between selected variables in postmenopausal women

\begin{tabular}{lcc} 
Variables & $\mathrm{r}$ & $\mathrm{p}$ \\
\hline $\mathrm{SM}[\mathrm{kg}] \mathrm{vs}$. TUG [s] & -0.22 & $0.00^{*}$ \\
$\mathrm{SM}[\mathrm{kg}]$ vs. CST [rep/s] & 0.09 & 0.29 \\
$\mathrm{SMI}\left[\mathrm{kg} / \mathrm{m}^{2}\right]$ vs. TUG [s] & -0.22 & $0.00^{*}$ \\
$\mathrm{SMI}\left[\mathrm{kg} / \mathrm{m}^{2}\right]$ vs. CST [rep/s] & 0.16 & $0.04^{*}$ \\
CST [rep/s] vs. TUG [s] & -0.47 & $0.00^{*}$ \\
\hline Abbreviations: SM - skeletal muscle mass; SMI - skeletal muscle mass index; TUG - timed-up-and-go; CST - 30-second chair stand; *p<0.05
\end{tabular}

Analysis of the results showed a statistically significant negative correlation between SM vs. TUG, and SMI vs. TUG $(r=-0.22 ; \mathrm{p}=0.00)$. The results suggest that as SM and SMI increase, the level of mobility among older women in the community improves (TUG test time is reduced).

There was also a significant positive relationship of SMI vs. CST ( $r=0.16 ; p=0.04)$, while the relationship of SM vs. CST was not statistically significant $(r=0.09 ; p=0.29)$. This result may suggest that the SMI parameter was more effective in predicting the lower 
extremity strength in subjects than SM. However, taking into account that the differences in the strength of correlation between the analyzed coefficients were small $(\Delta \mathrm{r}=0.07)$, it was decided that assuming the foregoing hypothesis was not justified. This is confirmed by the significance test which showed no differences $(p=0.52)$ between SM vs. CST and SMI vs. CST correlations.

However, the strongest relationship was observed in the case of CST vs. TUG ( $r=-0.47$; $\mathrm{p}=0.00$ ). This relationship suggests that the level of mobility among the examined women improves with the increase in functional strength of the lower extremities. Further statistical analysis using Fisher's transformation showed that differences in correlation strength between SMI vs. TUG, SM vs. TUG and CST vs. TUG were statistically significant $(p=0.01)$. This result shows that functional strength of the lower extremities was a better parameter for predicting mobility in older women than SMI and SM.
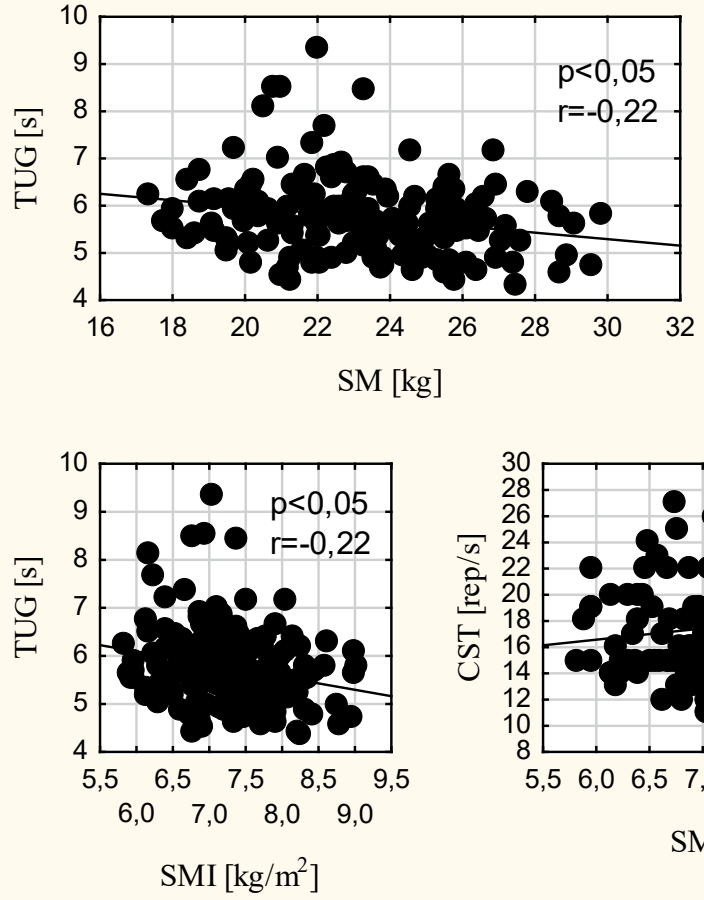
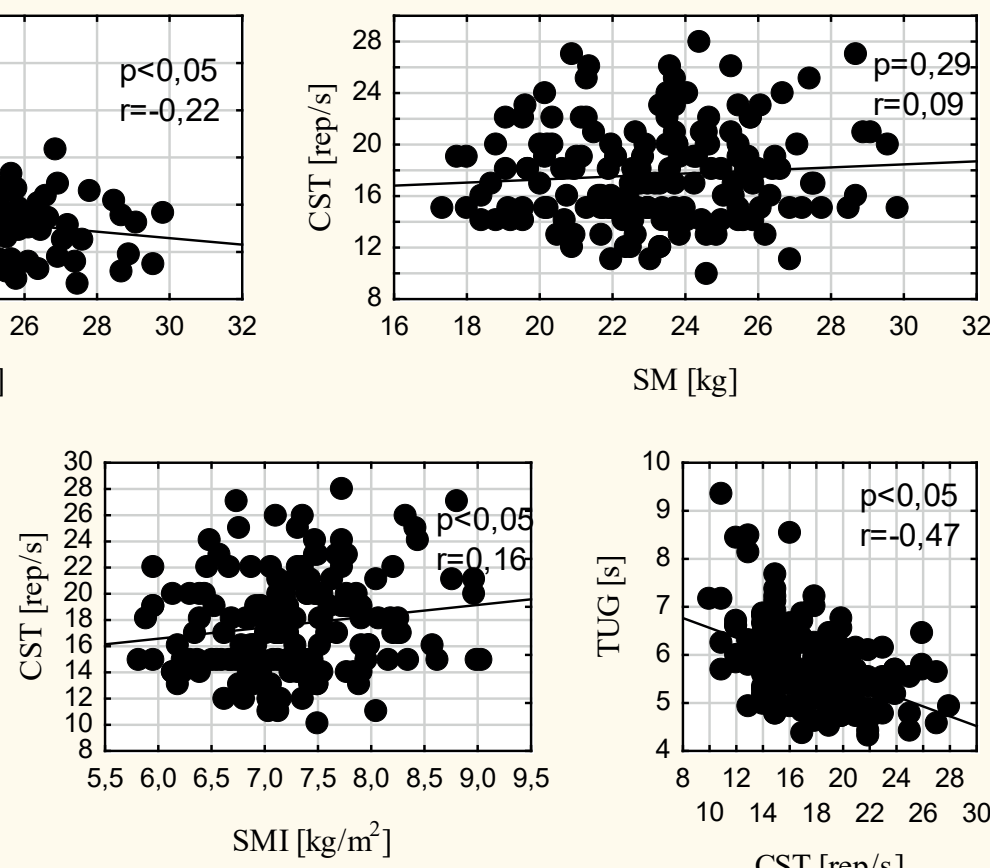

$\mathrm{SMI}\left[\mathrm{kg} / \mathrm{m}^{2}\right]$

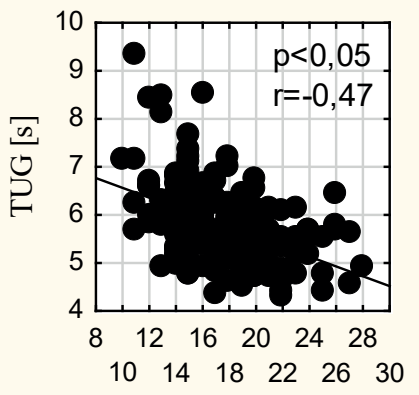

CST $[\mathrm{rep} / \mathrm{s}]$

Fig. 1 Correlation results between selected variables in the studied women

Abbreviations: SM - skeletal muscle mass; SMI - skeletal muscle mass index; TUG - timed-up-and-go; CST - 30-second chair stand

\section{DISCUSSION}

Sarcopenia may lead to mobility restrictions affecting $25-75 \%$ of people at the age of 65 years and older [27]. Understanding the relationship between SMI and strength with mobility constraints is therefore very important from both the social and clinical point of view [28].

Studies have shown a significant relationship between SMI, SM and mobility measured in the TUG test. The hypothesis of the relationship between SMI, SM and the functional strength of the lower extremities measured in the CST test was rejected in further studies.

No studies documenting the relationship between SMI and TUG test results were found in the literature, making it difficult to relate the obtained results. However, some researchers 
noted that the marching time in the TUG test may be a strong indicator of sarcopenia [23] and frailty syndrome [29]. Given that SMI is the main indicator for the diagnosis of sarcopenia and it has shown a significant relationship with mobility, this study partially confirms these observations.

Over the course of longitudinal studies, other researchers have noted that age-related decline in muscle strength is not proportional to muscle mass loss [30, 31]. Delmonico et al. [32] confirmed that maintaining SM or increasing SM did not prevent the agerelated decrease in muscle strength. Having considered the foregoing reports, it can be assumed that measurements of skeletal muscle mass and strength should be performed independently in older people. The absence of a relationship between SM and functional strength of the lower extremities has also been confirmed in this study.

The study also showed a positive relationship between the functional strength of the lower extremities measured in the CST test and the TUG test results.

In their study, Sillanpäää et al. [18] did not show a similar relationship between the isometric force of knee extensors and TUG test results in healthy individuals between 69 and 81 years of age. However, Benavent-Caballer et al. [17] found significant links between mobility in the TUG test with the Berg balance scale and the strength of knee extensors ( $\mathrm{r}=-0.561$ and -0.397 , respectively) in healthy elderly people living in Spain. Recent studies have also confirmed that low results in the TUG test were independently related to e.g. weakness of the lower extremities $(p=0.00 ; r=-0.43)$ and reduced balance in older people suffering from diabetes [33]. The results presented in this study were comparable $(p=0.00 ; r=-0.47)$, confirming a positive relationship between the functional strength of the lower extremities and the TUG results. It is worth noting, however, that the foregoing researchers used knee extensor strength tests, whereas our measurements involved CST functional leg strength test. However, studies by Hughes et al. [34] reported that elderly people use $97 \%$ of knee extensors when getting up from a low chair. Moreover, our earlier studies showed a statistically significant positive correlation $(r=0.23 ; p=0.03)$ between the GS test gait speed and the CST test results [35]. Therefore, the presented results may indicate the potential usefulness of a simple to perform, functional 30-second chair stand to predict low mobility in older women.

The results also suggest that functional strength of the lower extremities was a significantly better parameter in predicting mobility in older women, compared to SMI and SM.

Our observations partially confirm the results obtained by Visser et al. [36]. The authors showed that lower muscle mass (smaller cross-sectional muscle area), lower muscle strength and higher fat infiltration in skeletal muscle were associated with mobility limitations in elderly men and women. Over the course of further analyses, the authors concluded that the relationship between low muscle mass and incident mobility limitations seemed to be a function of lower muscle strength.

The results obtained in this study are important, because muscle function decreases are observed with age, particularly in women, thus resulting in impaired mobility and collapsing [37]. Thus, limited mobility significantly increases the likelihood of sarcopenia. Other researchers also point out that the ability to perform mobility-based activities of daily living, such as: walking up the stairs, walking around a room, getting up from a chair or bed, maintaining balance in a standing position, is a predictor of developing disability, dependence and mortality [38]. 


\section{LIMITATIONS}

The performed study had some limitations. Firstly, no sarcopenia was found in the subjects, and they were characterized by relatively good physical performance. Secondly, the bioelectrical impedance analysis (BIA) method was used in the tests to measure SM. However, according to EWGSOP, bioimpedance tests can be an alternative to DXA tests to determine SM and SMI [39]. Moreover, the studies did not analyze other factors that could affect the function of the muscular system, such as inflammation and neurological disorders. In the future, it is also worth considering cognitive functions, as following the latest research, the level of these functions may be related to the occurrence of sarcopenia among women [40]. Nevertheless, the aforementioned limitations may have influenced the study results and thus increased the likelihood of their underestimation.

\section{CONCLUSIONS}

There was a significant relationship found between SMI, SM, functional strength of the lower extremities and mobility in older women. However, the strength of lower extremities was a better parameter in predicting mobility in older women than SMI and SM. The results may be helpful for doctors and therapists in the diagnosis of mobility limitations, as well as for trainers in the process of programming physical activity of older women, aimed at preventing sarcopenia.

\section{REFERENCES}

[1] Fielding RA, Vellas B, Evans WJ, et al. Sarcopenia: an undiagnosed condition in older adults. Current consensus definition: prevalence, etiology, and consequences. International working group on sarcopenia. J Am Med Dir Assoc. 2011;12(4):249-256. doi:10.1016/j.jamda.2011.01.003

[2] Ossowski ZM, Skrobot W, Aschenbrenner P, Cesnaitiene VJ, Smaruj M. Effects of short-term Nordic walking training on sarcopenia-related parameters in women with low bone mass: a preliminary study. Clin Interv Aging. 2016;11:17631771. doi:10.2147/CIA.S118995

[3] Janssen I, Heymsfield SB, Wang ZM, Ross R. Skeletal muscle mass and distribution in 468 men and women aged 18-88 yr. J Appl Physiol. 2000;89(1):81-88. doi:10.1152/jappl.2000.89.1.81

[4] Frontera WR, Hughes VA, Fielding RA, Fiatarone MA, Evans WJ, Roubenoff R. Aging of skeletal muscle: a 12-yr longitudinal study. J Appl Physiol. 2000;88(4):1321-1326. doi:10.1152/jappl.2000.88.4.1321

[5] Ossowski ZM. Trening zdrowotny a sarkopenia u kobiet w okresie pomenopauzalnym [Health Training and Sarcopenia in Postmenopausal Women). Gdańsk: AWFiS; 2019. Polish.

[6] Webber SC, Porter MM, Menec VH. Mobility in Older Adults: A Comprehensive Framework. Gerontologist. 2010;50(4):443-450. doi:10.1093/geront/gnq013

[7] Topinková E. Aging, disability and frailty. Ann Nutr Metab. 2008;52 Suppl 1:6-11. doi:10.1159/000115340

[8] Scott D, Daly RM, Sanders KM, Ebeling PR. Fall and Fracture Risk in Sarcopenia and Dynapenia With and Without Obesity: the Role of Lifestyle Interventions. Curr Osteoporos Rep. 2015. doi:10.1007/s11914-015-0274-z

[9] Yeung SSY, Reijnierse EM, Pham VK, et al. Sarcopenia and its association with falls and fractures in older adults: A systematic review and meta-analysis. J Cachexia Sarcopenia Muscle. 2019;10(3):485-500. doi:10.1002/jcsm.12411

[10] Brown JC, Harhay MO, Harhay MN. Sarcopenia and mortality among a population-based sample of communitydwelling older adults. J Cachexia Sarcopenia Muscle. 2016;7(3):290-298. doi:10.1002/jcsm.12073

[11] Edwards MH, Dennison EM, Aihie Sayer A, Fielding R, Cooper C. Osteoporosis and sarcopenia in older age. Bone. 2015;80:126-130. doi:10.1016/j.bone.2015.04.016

[12] Nakamura K. The concept and treatment of locomotive syndrome: its acceptance and spread in Japan. J Orthop Sci. 2011;16(5):489-491. doi:10.1007/s00776-011-0108-5

[13] Sasaki E, Ishibashi Y, Tsuda E, et al. Evaluation of locomotive disability using loco-check: a cross-sectional study in the Japanese general population. J Orthop Sci. 2013;18(1):121-129. doi:10.1007/s00776-012-0329-2

[14] Yoshimura N, Muraki S, Oka H, et al. Association between new indices in the locomotive syndrome risk test and decline in mobility: third survey of the ROAD study. J Orthop Sci. 2015;20(5):896-905. doi:10.1007/s00776-015-0741-5

[15] Singh MAF. Exercise Comes of Age: Rationale and Recommendations for a Geriatric Exercise Prescription. Journals Gerontol Ser A Biol Sci Med Sci. 2002;57(5):M262-M282. doi:10.1093/gerona/57.5.M262

[16] Cruz-Jentoft AJ, Baeyens JP, Bauer JM, et al. Sarcopenia: European consensus on definition and diagnosis: Report of the European Working Group on Sarcopenia in Older People. Age Ageing. 2010;39(4):412-423. doi:10.1093/ageing/afq034

[17] Benavent-Caballer V, Sendín-Magdalena A, Lisón JF, et al. Physical factors underlying the Timed “Up and Go" test in older adults. Geriatr Nurs (Minneap). 2016;37(2):122-127. doi:10.1016/j.gerinurse.2015.11.002

[18] Sillanpää E, Stenroth L, Bijlsma AY, et al. Associations between muscle strength, spirometric pulmonary function and mobility in healthy older adults. Age (Omaha). 2014;36(4):9667. doi:10.1007/s11357-014-9667-7 
[19] Krzymińska-Siemaszko, R Czepulis, N Rzepnicka, A Dworak, L Wieczorowska-Tobis K. Ocena ryzyka sarkopenii u starszych kobiet [Assessment of the risk of sarcopenia in elderly women]. Now Lek. 2013;82(1):19-24. Polish. doi: $10.1155 / 2014 / 450396$

[20] Zembroń-Łacny A, Dziubek W, Rogowski Ł, Skorupka E, Dąbrowska G. Sarcopenia: monitoring, molecular mechanisms, and physical intervention. Physiol Res. 2014;63(6):683-691. doi: 10.33549/physiolres.932692

[21] Dong R, Wang X, Guo Q, et al. Clinical Relevance of Different Handgrip Strength Indexes and Mobility Limitation in the Elderly Adults. Journals Gerontol Ser A Biol Sci Med Sci. 2016;71(1):96-102. doi:10.1093/gerona/glv168

[22] Greene BR, Doheny EP, O’Halloran A, Anne Kenny R. Frailty status can be accurately assessed using inertial sensors and the TUG test. Age Ageing. 2014;43(3):406-411. doi:10.1093/ageing/aft176

[23] Martinez BP, Gomes IB, Oliveira CS de, et al. Accuracy of the Timed Up and Go test for predicting sarcopenia in elderly hospitalized patients. Clinics (Sao Paulo). 2015;70(5):369-372. doi:10.6061/clinics/2015(05)11

[24] Rikli RE, Jones CJ. Development and Validation of a Functional Fitness Test for Community-Residing Older Adults. J Aging Phys Act. 1999;7(2):129-161. doi:10.1123/japa.7.2.129

[25] Martien S, Delecluse C, Boen F, et al. Is knee extension strength a better predictor of functional performance than handgrip strength among older adults in three different settings? Arch Gerontol Geriatr. 2015;60(2):252-258. doi:10.1016/j.archger.2014.11.010

[26] Toots A, Rosendahl E, Lundin-Olsson L, Nordström P, Gustafson Y, Littbrand H. Usual Gait Speed Independently Predicts Mortality in Very Old People: A Population-Based Study. J Am Med Dir Assoc. 2013;14(7):529.e1-529.e6. doi:10.1016/j.jamda.2013.04.006

[27] Sackley CM, van den Berg ME, Lett K, et al. Effects of a physiotherapy and occupational therapy intervention on mobility and activity in care home residents: a cluster randomised controlled trial. BMJ. 2009;339(sep01 2):b3123b3123. doi:10.1136/bmj.b3123

[28] IJmker, T Lamoth C. The relationship between gait stability and variability with executive function in persons with and without dementia. Gait Posture. 2012;35(1):126-130. doi: 10.1016/j.gaitpost.2011.08.022

[29] Savva GM, Donoghue OA, Horgan F, O’Regan C, Cronin H, Kenny RA. Using Timed Up-and-Go to Identify Frail Members of the Older Population. J Gerontol A Biol Sci Med Sci. 2013;68(4):441-446. doi:10.1093/gerona/gls190

[30] Clark BC, Manini TM. Sarcopenia =/= dynapenia. J Gerontol A Biol Sci Med Sci. 2008;63(8):829-834. doi:10.1093/ gerona/63.8.829

[31] Goodpaster BH, Park SW, Harris TB, et al. The Loss of Skeletal Muscle Strength, Mass, and Quality in Older Adults: The Health, Aging and Body Composition Study. J Gerontol A Biol Sci Med Sci. 2006;61(10):1059-1064. doi:10.1093/ gerona/61.10.1059

[32] Delmonico MJ, Harris TB, Visser M, et al. Longitudinal study of muscle strength, quality, and adipose tissue infiltration. Am J Clin Nutr. 2009;90(6):1579-1585. doi:10.3945/ajcn.2009.28047

[33] Wettasinghe AH, Dissanayake DW, Katulanda P, Lord SR. Timed up and go performance in older people with diabetes mellitus: associations with sensorimotor function, balance, cognition, and falls. Int J Physiother. 2020;7(2). doi:10.15621/ijphy/2020/v7i2/655

[34] Hughes MA, Myers BS, Schenkman ML. The role of strength in rising from a chair in the functionally impaired elderly. J Biomech. 1996;29(12):1509-1513. doi:10.1016/S0021-9290(96)80001-7

[35] Ossowski, ZM Wiech, M Ellwart M. The relationship between gait speed and muscle mass \& strength in postmenopausal women. Balt J Heal Phys Act. 2019;11(1):106-114. doi: 10.29359/BJHPA.11.1.11

[36] Visser M, Goodpaster BH, Kritchevsky SB, et al. Muscle Mass, Muscle Strength, and Muscle Fat Infiltration as Predictors of Incident Mobility Limitations in Well-Functioning Older Persons. Journals Gerontol Ser A Biol Sci Med Sci. 2005;60(3):324-333. doi:10.1093/gerona/60.3.324

[37] Moreland JD, Richardson JA, Goldsmith CH, Clase CM. Muscle Weakness and Falls in Older Adults: A Systematic Review and Meta-Analysis. J Am Geriatr Soc. 2004;52(7):1121-1129. doi:10.1111/j.1532-5415.2004.52310.x

[38] Guralnik JM, Ferrucci L, Simonsick EM, Salive ME, Wallace RB. Lower-Extremity Function in Persons over the Age of 70 Years as a Predictor of Subsequent Disability. N Engl J Med. 1995;332(9):556-562. doi:10.1056/ NEJM199503023320902

[39] Wang H, Hai S, Cao L, Zhou J, Liu P, Dong B-R. Estimation of prevalence of sarcopenia by using a new bioelectrical impedance analysis in Chinese community-dwelling elderly people. BMC Geriatr. 2016;16(1):216. doi:10.1186/ s12877-016-0386-z

[40] Liu X, Hou L, Xia X, et al. Prevalence of sarcopenia in multi ethnic adults and the association with cognitive impairment: findings from West-China health and aging trend study. BMC Geriatr. 2020;20(1):63. doi:10.1186/s12877-020-1468-5 